\title{
Financial Well-Being in an Urban Area: An Application of Multiple Imputation ${ }^{\dagger}$
}

\author{
David A. Penn* \\ Middle Tennessee State University, Murfreesboro,
}

\begin{abstract}
A growing number of studies investigate the determinants of happiness, or subjective well-being. Few, however, specifically examine the financial aspects of subjective well-being. This study estimates the determinants of subjective financial wellbeing (SWB) for a city in the American Southwest. The results show that income, health insurance, home ownership, and children at home have significant impacts on financial well-being. Missing survey values are estimated using multiple imputation; model results with and without imputed data are compared. Estimates from the complete case model show bias compared with the multiple imputation model. Home ownership and children at home are important predictors of financial well-being in the multiple imputation model but not the complete cases model.
\end{abstract}

Keywords: subjective well-being, financial well-being, multiple imputation

JEL Categories: A10, C42

\footnotetext{
$\dagger$ The author thanks the anonymous referee and Joachim Zietz for many helpful comments. Data collection for this study was supported by a contract with Community Council of Central Oklahoma, Inc. An earlier version of this paper was presented at the Academy of Economics and Finance annual meeting in Myrtle Beach, South Carolina, in February 2005.

* Business and Economic Research Center and Department of Economics and Finance, Middle Tennessee State University, Murfreesboro, TN 37132, email: dpenn@mtsu.edu.
} 


\section{Introduction}

The quantity of research on the determinants of happiness and subjective wellbeing is growing quickly in the economics literature. ${ }^{1}$ The dependent variable in most of these studies is overall satisfaction or well-being; only a few studies specifically model financial well-being as the dependent variable. Also, nearly all of the studies are based on survey data, and none addresses the issue of how to deal with missing values that almost always are found in survey data. Bukenya et al. (2003), for example, model selfreported quality of life in West Virginia with questionnaire data collected by mail; the researchers offer no discussion of income non-response or how missing information is handled. Using data from the German Socio-Economic Panel, van Praag et al (2003) estimate various domains for subjective well-being. A large number of observations $(19,000)$ are used in the study, but the authors do not discuss the prevalence of missing information or what is done with observations that have missing information. McBride (2001) analyzes subjective well-being in the U.S. using data from the General Social Survey. Starting with more than 2,000 observations, he excludes dozens of observations with missing values. After the exclusions and deletions, his model estimates are based on 324 observations. The author offers no discussion regarding possible bias and inefficiency created by deleting incomplete observations. ${ }^{2}$

Recent studies of subjective well-being (SWB) rely heavily on survey data, but none adequately addresses an important issue: how best to deal with missing survey information? Missing information of concern in this paper consists of item non-response,

\footnotetext{
${ }^{1}$ Kahneman and Krueger (2006) and DiTella and MacCulloch (2006) provide overviews of happiness and subjective well-being.

${ }^{2}$ Penn (2007) provides an example of using multiple imputation to estimate missing values in the General Social Survey.
} 
defined as a refusal to respond or simply a lack of response to a particular survey question. The manner in which researchers choose to deal with missing information can significantly affect parameter estimates and standard errors (Schafer 1997). Simply deleting incomplete observations is acceptable in some, but not all, circumstances. Estimating, or imputing, the missing information may be a more methodologically sound approach. This study applies an approach for estimating missing values that has become relatively well developed in the statistics and public health literatures ${ }^{3}$ but has received less attention from economists.

This study models the determinants of financial well-being for a city in the Southwest United States using survey data adjusted for item non-response. Specifically, multiple imputation is used to estimate missing values in a survey of financial well-being conducted in Oklahoma County, Oklahoma. This study proceeds as follows. First, a brief overview of the current literature regarding happiness and financial well-being is offered, followed by an introduction to missing data and multiple imputation. The next section describes the original data used in the study. A model of financial well-being is discussed next, followed by an analysis of the ordered logit model estimates. Conclusions are offered in the final section.

\section{Happiness and Financial Well-Being}

An increasing amount of evidence in the literature shows how subjective wellbeing depends on a variety of variables and characteristics, in addition to income. Other important predictors for well-being include education, working status, health status, and

\footnotetext{
${ }^{3}$ Raghunathan (2004) is a recent example in the public health literature. Schafer and Graham (2002) provide an excellent discussion of the principles and applications of multiple imputation.
} 
marital status (Headey and Wooden, 2004), whether the individual has health insurance (Bender, 2004), and the political environment in which the individual lives (Frey and Stutzer, 2002). The effects of social variables (religion, for example) have been estimated (Soydemir et al., 2004), and social capital, including perceptions of government quality, has received attention (Helliwell, 2006). Winkelmann (2005) shows individual well-being is interdependent within a family; well-being reported by children, for example, is strongly correlated with parents' well-being. Using data from 80 countries, Borooah (2006) finds that good health is an important predictor of selfreported happiness, as are being married, belonging to a voluntary organization, and high educational attainment.

Studies that model subjective financial well-being, instead of overall well-being or happiness, are scarce. In one example, van Praag et al (2003) show that financial wellbeing (financial satisfaction is their term) can be considered one of six major contributors to general satisfaction or happiness, with the other major components being job satisfaction, housing satisfaction, leisure satisfaction, health satisfaction, and satisfaction with one's surroundings (environment satisfaction). Using the German Socio-Economic Panel, the study examines how financial satisfaction depends on age, income, savings, education, the number of children, the number of adults, and gender. Notably, the number of children living in the household has a negative effect on financial satisfaction.

A British study analyzes the determinants of both life satisfaction and satisfaction with income, the latter resembling financial well-being. Drawing data from the British Household Panel Survey, Burchardt (2004) finds that tenure (owning versus renting a 
home), the number of children, marital status, income, age, and disability status all matter for the purpose of explaining income satisfaction.

To summarize the literature, income, demographic characteristics, health status, the number of children, and housing tenure are all important predictors of financial wellbeing. This study builds on the literature in three ways. First, many of the results found in the literature are replicated using unique primary data collected for a city in the American Southwest. Second, the study shows how model results can be biased by deleting incomplete observations. Finally, the study examines in detail the effect of children at home on subjective financial well-being.

\section{Multiple Imputation}

Deleting records with missing values is a common practice for dealing with missing values. Termed list-wise deletion, reducing the dataset down to just the complete cases has its advantages: it offers simplicity, since standard statistical packages can now be easily applied, and comparability, as all calculations proceed from a common base (Little and Rubin, 2002). List-wise deletion is simple and may be perfectly appropriate in numerous situations, particularly if the number of deleted incomplete cases is relatively small or if the deleted cases are very similar to the complete cases.

In many situations, however, discarding incomplete cases creates disadvantages.

First, estimates based on complete cases are biased if the deleted cases differ from the complete cases. Second, the precision of model estimates will be lower due to the smaller sample size. It is possible that the extent of the bias and loss of precision will be small; rules of thumb are difficult to formulate, however, since the degree of bias depends 
not only on the proportion of incomplete cases but also on the differences between complete and incomplete cases and the pattern of missing data (Little and Rubin, 2002).

Multiple imputation offers an alternative to simply deleting observations with missing information. In multiple imputation (MI), the researcher generates several estimates for each missing value. ${ }^{4}$ In practice, the multiple estimates will differ, and the variation of the estimates can be used to statistically measure the uncertainty of imputation. Other missing data techniques are available but have serious shortcomings. Simply replacing a missing value with its mean value, for example, has the undesired effect of biasing variance and covariance estimates toward zero. Using regression estimates to predict the missing data is also problematic, as the filled in data will automatically be correlated with the predictor data.

Typically five or more estimates are generated for each missing value in multiple imputation; these are combined with the complete cases, with each combined dataset containing missing value estimates and a replicate of the complete cases. The estimated values will typically differ from dataset to dataset. Regression models (or other statistics) are then estimated separately for each of the datasets; the separate regression parameter estimates are then combined to obtain overall estimates.

Several MI software packages are now available. This study uses IVEware, developed by the University of Michigan Survey Research Center. ${ }^{5}$ IVEware offers several advantages. First, the software automatically chooses the distributional form that is most appropriate for the variable: a logistic model for binary variables, a regression

\footnotetext{
${ }^{4}$ An earlier example in this journal of a study of the use of multiple imputation in this journal may be found in Keng, Garasky, and Jensen (2002).

${ }^{5}$ IVEware software and documentation are available at http://www.isr.umich.edu/src/smp/ive/.
} 
model for continuous variables, and a generalized logistic model for multi-valued categorical variables, for instance. Second, like other multiple imputation packages, IVEware can simultaneously estimate missing values for several variables. But unlike other techniques, IVEware employs an iterative algorithm that sequentially chooses the predictor variables that do the best job of predicting the missing values.

\section{Description of the Data}

Data for this study were collected by the Center for Economic and Management Research, The University of Oklahoma, under contract with Community Council of Oklahoma County, a not-for-profit social services agency responsible for coordinating research needs for local social service agencies. Community Council desired an annual indicator of quality of life for Oklahoma County with particular attention to the elderly and households with children. Randomly selected householders were interviewed by telephone during the spring of 2002. The phone number sample was generated by random digit dialing, and the sample was stratified by age and gender. A response rate of 45 percent was achieved, resulting in 1,265 interviews. $^{6}$

Items from the survey in the present study including financial well-being, age, the presence of children under 18 years at home, household income, home ownership, whether the householder has health insurance, gender, education, marital status, and working status. Why these variables are chosen will be discussed in the next two sections. Variable descriptions and summary statistics are offered in Table 1. Financial well-being (FWB) is the response to the question, "How would you say you feel about the overall financial security of your household? Would you say you feel very secure,

\footnotetext{
${ }^{6}$ More discussion of the study and general descriptive statistics may be found in Penn, 2005.
} 
somewhat secure, somewhat insecure or very insecure?" The number of householders who respond somewhat insecure to this question is very small; consequently, FWB is recoded from four values to three, with not secure combined from somewhat insecure and very insecure.

Overall, 21.1 percent of the sample has data missing for one or more variables (Table 2). Most of the missing information is attributable to income, followed by age and marital status.

\section{A Model of Financial Well-Being}

As demonstrated in the literature, subjective financial well-being is thought to depend on income, demographic characteristics including sex, race, education, and age, and situational characteristics such as health insurance, children at home, employment status, and marital status. Examining the Oklahoma County data, it is clear that income and financial well-being are positively related as one would expect (Table 3). As household income rises, so does self-reported financial security: 51.3 percent in the highest income category report they are very secure in their financial situation, compared with just 20.8 percent of those in the lowest income category. Conversely, smaller incomes tend to be associated with financial insecurity: 33.1 percent in the lowest income category are not secure, compared with only 6.9 percent with the largest incomes. Other than the positive association between financial security and income, two other things are evident from the table. First, the connection between income and financial security is not as strong as one might have supposed. After all, households in the highest income category (At least $\$ 75,000$ ) have incomes that are twice as high as the median 
household for Oklahoma County, yet just a little more than half say they are very secure financially. Second, financial security does not measurably improve after a household reaches the 50,000-75,000 level; households with incomes of 75,000 and more are only slightly more secure than those in the 50,000-75,000 category. An income threshold effect appears to come into play, as increasing the household income beyond $\$ 75,000$ has little effect on financial security.

Financial well-being is displayed for various age groups in Table 4. Financial well-being is highest in the tails of the age distribution, producing the characteristic Ushaped relationship that is characteristic in several studies. Positive financial well-being, as measured by the percent very secure, is lowest in the 25-34 age category, and negative financial well-being (percent not secure) peaks in the 45-55 age group, making the peaks and troughs of financial security not quite symmetric by age.

Other variables that are likely to be related with financial well-being include home ownership, health insurance, educational attainment, and marital status. Home ownership is an important financial consideration, since a home is a major component of household wealth. When housing prices are rising, a home owner may tap the equity in her home to reduce credit card debt, pay for children's college expenses, pay for a vacation, a new car, and other purchases. Also, rising equity values offer peace-of-mind; the homeowner knows she can use the equity in her home if needed to pay for unanticipated expenses such as medical bills, or the loss of a job for a member of the household. Table 5 shows a strong association between home ownership and financial well-being.

Private health insurance offers partial protection against catastrophic financial 
loss due to large medical expenses, regardless of whether the premiums are paid by the household or the employer, thereby contributing to a household's financial security. In addition, employer-provided health insurance is an important and fast growing component of compensation, thus directly affecting the economic status of households. In our sample, households without private health insurance are much less financially secure than households with health insurance (Table 5).

Educational attainment also tends to be related to financial well-being. Those with a Bachelor's degree report greater financial well-being than those without a college degree (Table 5). A college degree is strongly associated with higher incomes, better job security, and lower unemployment rates, all positive contributions to financial wellbeing. Educational attainment may also be correlated with wealth.

The number of children at home is sometimes overlooked as a factor that affecting financial well-being. This study shows that households with children at home report a lower level of financial well-being than similar households without children. To be sure, parents receive immense satisfaction from raising children; raising children undoubtedly increases parents' overall well-being. But as a purely financial matter, raising a child is a large commitment. According to the U.S. Department of Agriculture, a husband-wife family of middle income can expect to use 26 percent of household expenditures to raise one child, rising to 42 percent for two children. In constant 2005 dollars, this amounts to $\$ 190,980$ to raise one child from birth to 17 years (Lino, 2006). For most families, the cost of raising children is either the first or second largest financial commitment they will undertake, surpassed possibly by the cost of a home.

Table 6 presents pair-wise correlations for the most important categorical 
variables; not surprisingly, income, health insurance, and home ownership are positively related with financial well-being. Several of the explanatory variables are strongly correlated with each other, some more so than with financial well-being. Interestingly, race (Black) affects financial well-being directly but also indirectly through income, home ownership, health insurance, marital status, children at home, and educational attainment.

\section{Estimating the Ordered Logit Models}

Ordered logit models are estimated with financial well-being as the dependent variable and income, age, education, number of children, home ownership, health insurance, sex, working, status, race, and marital status on the right-hand side. These particular explanatory variables are chosen because they have support in the literature, and because there is a reasonably strong theoretical basis for inclusion (discussed above for home ownership, health insurance, number of children, and educational attainment). Following the literature (van Praag et al, 2003) age is modeled as a second-order polynomial, thus capturing the expected concave relationship between age and financial well-being.

Table 7 presents estimates for the multiple imputation model (MI) and the complete cases model (CC). The MI parameter estimates are the means of the estimates from the five separate regressions. Standard errors also are combined, taking into account both variance within each imputation and variance between imputations. Fortunately, the MI software accomplishes these tasks.

The fit and predictive power of the models appears reasonable, judging from R- 
squared, the Wald statistic, and percent concordant. Also, the proportional odds assumption cannot be rejected as shown by the high p-value for the score test.

The MI model is estimated using all available information, 1,148 observations, ${ }^{7}$ but the complete cases model uses only those observations with no missing information, a total of 910. Comparing the MI and CC results, we find that estimates for health insurance are very similar and p-values are very small. Educational attainment (College) is also very similar and highly significant. The most important difference between the MI and CC models has to do with home ownership and one child at home; both have low p-values in the MI model, but neither are significant in the $\mathrm{CC}$ model. For most other variables, the coefficient estimates are smaller in the MI model than the CC model. Standard errors also are smaller in the MI model, but the difference is not large. The MI standard errors are the results of opposing forces; on the one hand, the larger sample size pushes down the standard errors, but on the other hand the standard errors are increased by the between-imputation variation. The net result is that standard errors are somewhat smaller.

Table 8 shows the bias from using the $\mathrm{CC}$ model. Predicted probabilities for each of the three levels of financial well-being are displayed for both models, using mean values for the explanatory variables. The bias is substantial, with the predicted probability for very secure model 6 points lower for the CC model than the MI model, and not secure is 2.6 points higher. Thus, using only the complete observations, one would conclude that Oklahoma County households are less financially secure than is likely the case. Moreover, one would conclude, erroneously, that home ownership and having one child in the home are not significant predictors of financial well-being. When

\footnotetext{
${ }^{7}$ Since college attainment is included as an explanatory variable, the sample is limited to ages 25 and older.
} 
we estimate the model using multiple imputations for missing values, thereby using all the available observations, we find that both home ownership and one child at home have strong predictive power for financial well-being.

\section{Financial Well-Being and Children at Home}

An important story that emerges from the MI model is the negative relationship between children at home and financial well-being. This section explores this connection in more detail. To accomplish this, logit models are estimated for four subsets of the sample: males, females, married, and not married.

Logit estimate details are shown in Table 9. Model fit and predictive power are best for the not married group, and weakest for the married group. All but the married group passes the score test of the proportional odds assumption.

The results show differences among the four groups. Home ownership, for example, is a more important predictor of financial well-being for males than females, and more important for those married rather than not married. For females and those not married, health insurance is important than for males and married. Adding one child has much more influence on male financial well-being than the other groups.

Using these logit estimates, I compute predicted probabilities for the three levels of financial well-being given the household has no children, one child, or two or more children. All the other variables are held at their mean values (Table 10).

The predicted probabilities (Table 11) show the effect on financial well-being when one or more children are 'added' to the household. Considering all respondents, adding one child to the household raises the probability that the household is not secure 
financially, and decreases the probability that the household is very secure; the probability of very secure drops from 0.353 to 0.263 , a decrease of nine percentage points, and the probability of not secure increases by 5.4 points. The decline in financial well-being from adding one child is much more pronounced among males, decreasing 12.6 percentage points, compared with a drop of just 5.5 percentage points for females.

When married householders are compared with those who are not married, some interesting differences result. First, among households with no children, married are much more secure than not married. Second, the effect of adding children affects married households much less than not married households. Adding one child decreases very secure about equally for married and not married, but the probability of not secure increases much more $(+8.6$ points) for not married compared with married $(+3.8$ points). When two or more children are added, however, the difference between married and not married is much larger in comparison with no children. Married households experience a moderate decline in financial well-being, with very secure dropping 5.7 points and not secure rising 2.3 points. Not married households suffer a large negative effect, with very secure dropping 15.1 points and not secure jumping up greatly by 22.1 points.

\section{Summary and Conclusions}

This study estimates a model of financial well-being, using data collected from households in Oklahoma County, Oklahoma. Ordered logit models show how subjective financial well-being is sensitive to home ownership, educational attainment, health insurance, age, working status, and whether the household has children at home. Increasing income contributes to financial well-being up to a point. The marginal effects 
of adding children are negative for each of the four subset regressions estimated, but most negative for parents who are not married.

Missing values are estimated using multiple imputation. Regression results using just the complete cases are biased compared with the multiple imputation model. In addition, home ownership and one child at home are important in the MI model but not in the $\mathrm{CC}$ model

The results suggest that public policies that encourage home ownership, educational attainment, and support for families with children will help boost financial well-being, as will better access to private health insurance. The results also show that researchers should be careful when using data with missing values. If observations with missing data are simply deleted, model estimates may be biased. Multiple imputation offers a comprehensive method of estimating missing values and estimating the uncertainty resulting from missing value estimates. 


\section{References}

Bender, K. (2004) The well-being of retirees: Evidence using subjective data, Center for Retirement Research at Boston College, unpublished manuscript.

Borooah, V. K. (2006) How much happiness is there in the world? A cross-country study, Applied Economics Letters, 13, 483-488.

Bukenya, J. O., Gebremedhin, T. G., and Shaeffer, P. V. (2003) Analysis of quality of life and rural development: evidence from West Virginia data, Growth and Change, 34, 20218 .

Burchardt, T. (2004) Are one man's rags another man's riches? Identifying adaptive expectations using panel data, unpublished manuscript, Centre for Analysis of Social Exclusion, London School of Economics. Available online:

http://sticerd.lse.ac.uk/case/staff/person.asp?UserID=802.

DiTella, R. and MacCulloch, R, A. (2006) Some uses of happiness data in economics, Journal of Economic Perspectives, 20, 25-46.

Frey, B. and Stutzer, A. (2002) Happiness and economics, Princeton University Press, Princeton and Oxford.

Headey, B. and Wooden, M. (2004) The effects of wealth and income on subjective wellbeing and ill-being, Economic Record, 80, S24-S33.

Helliwell, J. (2006) Well-being, social capital, and public policy: what's new?, The Economic Journal, 116, C34-C45.

Kahneman, D. and Krueger, A. (2006) Developments in the measurement of subjective well-being, Journal of Economic Perspectives, 20, 3-24.

Keng, S. H., Garasky, S. and Jensen, H. (2002) Welfare dependence and recidivism in an era of welfare reform, Applied Economics, 34, 2311-2323.

Lino, Mark. (2006) Expenditures on Children by Families, 2005, U. S. Department of Agriculture, Center for Nutrition Policy and Promotion, Miscellaneous Publication No. 1528-2005. Online:

www.cnpp.usda.gov/ExpendituresonChildrenbyFamilies.htm.

Little, R. J. A. and Rubin, D. B. (2002) Statistical Analysis with Missing Data, John Wiley \& Sons, Inc., Hoboken, N.J.

McBride, M. (2001) Relative-income effects on subjective well-being in the crosssection, Journal of Economic Behavior \& Organization, 45, 251-78. 
Penn, David A. (2005) Determinants of Self-Reported Financial Security for Oklahoma County Households, Oklahoma Business Bulletin, 73, 9-21.

Penn, David A. (2007) Estimating missing values in the general social survey: an application of multiple imputation, Social Science Quarterly, forthcoming.

Raghunathan, T. E. (2004) What do we do with missing data? Some options for analysis of incomplete data, Annual Review of Public Health, 25, 99-117.

Schafer, J. L. (1997) Analysis of Incomplete Multivariate Data, New York: Chapman \& Hall/CRC.

Schafer, J. L. and Graham, J. W. (2002) Missing data: our view of the state of the art, Psychological Methods, 7, 147-77.

Soydemir, G. A., Bastida, E. and Gonzaelz, G. (2004) The Impact of religiosity on selfassessments of health and happiness: evidence from the US Southwest, Applied Economics, 36, 665-672.

Van Praag, B. M. S., Frijters, P., and Ferrer-i-Carbonell, A. (2003) The anatomy of subjective well-being, Journal of Economic Behavior \& Organization, 51, 29-49.

Winkelmann, R. (2005) Subjective well-being and the family: Results from an ordered probit model with multiple random effects, Empirical Economics, 30, 749-761. 
Table 1. Variable Descriptions, Mean Values, and Standard Deviations

\begin{tabular}{|c|c|c|c|c|c|}
\hline $\begin{array}{l}\text { Variable } \\
\text { name }\end{array}$ & Description & Mean & $\begin{array}{l}\text { Standard } \\
\text { Deviation }\end{array}$ & Min & Max \\
\hline FWB & $\begin{array}{l}\text { Financial well-being ( } 1=\text { Very secure, } \\
2=\text { Somewhat secure, } 3=\text { Insecure) }\end{array}$ & 1.830 & 0.715 & 1 & 3 \\
\hline $\begin{array}{l}\text { Less than } \\
\$ 30 \mathrm{~K}\end{array}$ & Income less than $\$ 30,000$ & 0.339 & 0.507 & 0 & 1 \\
\hline$\$ 30 \mathrm{~K}-\$ 50 \mathrm{~K}$ & Income from $\$ 30,000$ to $\$ 50,000$ & 0.248 & 0.493 & 0 & 1 \\
\hline$\$ 50 \mathrm{~K}-\$ 75 \mathrm{~K}$ & Income from $\$ 50,000$ to $\$ 75,000$ & 0.276 & 0.483 & 0 & 1 \\
\hline $\begin{array}{l}\text { More than } \\
\$ 75 \mathrm{~K}\end{array}$ & Income more than $\$ 75,000$ & 0.137 & 0.486 & 0 & 1 \\
\hline $\mathrm{AGE}$ & Age of respondent & 47.418 & 17.348 & 18 & 99 \\
\hline $\begin{array}{l}\text { HOME } \\
\text { OWNER }\end{array}$ & $\begin{array}{l}\text { Home ownership }(1=\text { Home owner, } \\
0=\text { Not home owner })\end{array}$ & 0.717 & 0.451 & 0 & 1 \\
\hline CHILD1 & $\begin{array}{l}\text { One child under } 18 \text { in home } \\
\text { ( } 1=\text { Present, } 0=\text { Not present })\end{array}$ & 0.156 & 0.004 & 0 & 1 \\
\hline CHILD2 & $\begin{array}{l}\text { More than one child under } 18 \text { in home } \\
(1=\text { Present, } 0=\text { Not present })\end{array}$ & 0.218 & 0.005 & 0 & 1 \\
\hline MALE & $1=$ Male, $0=$ Female & 0.469 & 0.007 & 0 & 1 \\
\hline HEALTH & $\begin{array}{l}\text { Private health insurance (1=Have, } \\
0=\text { Don't have) }\end{array}$ & 0.803 & 0.399 & 0 & 1 \\
\hline NMARRY & $\begin{array}{l}\text { Marital status (1=Not married, } \\
0=\text { Married) }\end{array}$ & 0.395 & 0.492 & 0 & 1 \\
\hline NWORK & $\begin{array}{l}\text { Working status ( } 1=\text { Not working, } \\
0=\text { Working) }\end{array}$ & 0.074 & 0.262 & 0 & 1 \\
\hline COLLEGE & $\begin{array}{l}\text { Bachelor's Degree ( } 1=\text { Have, } 0=\text { Don't } \\
\text { have) }\end{array}$ & 0.343 & 0.479 & 0 & 1 \\
\hline
\end{tabular}

Note: the mean is computed over the five imputed datasets. The standard deviation reflects both within-imputation and between-imputation variance. Includes all respondents 18 years and older.

\begin{tabular}{cc}
$\begin{array}{c}\text { Sample by age } \\
\text { category }\end{array}$ & Percent \\
\hline $18-25$ & 9.2 \\
$25-34$ & 16.7 \\
$35-44$ & 20.5 \\
$45-54$ & 20.8 \\
$55-64$ & 13.4 \\
65 and older & 19.4 \\
\hline
\end{tabular}


Table 2. Values Missing by Variable

\begin{tabular}{lrr}
\hline Variable & $\begin{array}{r}\text { Number } \\
\text { Missing }\end{array}$ & $\begin{array}{r}\text { Percent } \\
\text { Missing }\end{array}$ \\
\hline Sex & 0 & 0.0 \\
Health insurance & 4 & 0.3 \\
Home owner & 5 & 0.4 \\
Children & 8 & 0.6 \\
Working status & 9 & 0.7 \\
Financial well-being & 16 & 1.3 \\
Education & 18 & 1.4 \\
Race & 18 & 1.4 \\
Marital status & 27 & 2.1 \\
Age & 51 & 4.0 \\
Income & 221 & 17.5 \\
At least one variable & & \\
missing & 267 & $21.1 \%$ \\
\hline
\end{tabular}


Table 3. Financial Well-Being by Income Category (Percent)

Household income (\$)

\begin{tabular}{lrrrrr} 
& Less than & $30,000-$ & $50,000-$ & At least & \\
Financial well-being & 30,000 & 49,999 & 74,999 & 75,000 & All \\
\hline Very secure & 20.8 & 31.0 & 48.4 & 51.3 & 35.1 \\
Somewhat secure & 46.1 & 54.3 & 43.4 & 41.7 & 36.8 \\
Not secure & 33.1 & 14.7 & 8.3 & 6.9 & 18.1 \\
\hline
\end{tabular}

Note: computed over the five imputed datasets. Includes all respondents 18 years and older. 
Table 4. Financial Well-Being by Age Category (Percent)

\section{Age}

\begin{tabular}{lrrrrrr} 
Financial well-being & $18-25$ & $25-34$ & $35-44$ & $45-54$ & $55-64$ & $\begin{array}{r}65 \text { and } \\
\text { older }\end{array}$ \\
\hline Very secure & 36.2 & 30.2 & 31.6 & 36.0 & 33.6 & 42.9 \\
Somewhat secure & 45.8 & 51.0 & 51.4 & 42.4 & 45.5 & 44.0 \\
Not secure & 18.0 & 18.8 & 17.0 & 21.7 & 20.9 & 13.1 \\
\hline
\end{tabular}

Note: computed over the five imputed datasets. Includes all respondents 18 years and older. 
Table 5. Financial Well-Being by Home Ownership, Health Insurance, and Bachelor's Degree (Percent)

\begin{tabular}{lrrrrrr}
\hline & \multicolumn{4}{c}{$\begin{array}{c}\text { Private health } \\
\text { Financial }\end{array}$} & Home ownership & \multicolumn{2}{c}{$\begin{array}{c}\text { Bachelor's } \\
\text { insurance }\end{array}$} & \multicolumn{2}{c}{ degree } \\
\cline { 2 - 7 } well-being & No & Yes & No & Yes & No & Yes \\
\hline Very secure & 21.0 & 40.6 & 17.4 & 39.5 & 28.6 & 47.5 \\
Somewhat secure & 48.6 & 46.1 & 43.2 & 47.7 & 48.7 & 43.2 \\
Not secure & 30.4 & 13.3 & 39.4 & 12.9 & 22.7 & 9.3 \\
\hline
\end{tabular}

Note: computed over the five imputed datasets. 
Table 6. Spearman Rank Correlations for the Categorical Variables

\begin{tabular}{|c|c|c|c|c|c|c|c|c|}
\hline Variable & Income & $\begin{array}{l}\text { Home } \\
\text { owner }\end{array}$ & $\begin{array}{c}\text { Health } \\
\text { insurance }\end{array}$ & $\begin{array}{c}\text { Bachelor's } \\
\text { degree }\end{array}$ & Male & Married & $\begin{array}{l}\text { Children } \\
\text { at home }\end{array}$ & Black \\
\hline $\begin{array}{l}\text { Financial } \\
\text { well-being }\end{array}$ & $0.339 * *$ & $0.254^{* *}$ & $0.280^{* *}$ & $0.224 * *$ & 0.047 & $0.170^{* *}$ & $-0.083 * *$ & $-0.145^{* *}$ \\
\hline Income & & $0.355^{* *}$ & $0.339 * *$ & $0.354 * *$ & $0.160^{* *}$ & $0.451 * *$ & $0.070 *$ & $-0.146^{* *}$ \\
\hline $\begin{array}{l}\text { Home } \\
\text { owner }\end{array}$ & & & $0.336^{* *}$ & $0.159 * *$ & $0.075^{*}$ & $0.284 * *$ & -0.044 & $-0.223 * *$ \\
\hline $\begin{array}{l}\text { Health } \\
\text { insurance }\end{array}$ & & & & $0.190 * *$ & 0.039 & $0.270^{* *}$ & 0.016 & $-0.135^{* *}$ \\
\hline $\begin{array}{l}\text { Bachelor's } \\
\text { degree }\end{array}$ & & & & & $0.098^{* *}$ & $0.143^{* *}$ & 0.051 & $-0.100 * *$ \\
\hline $\begin{array}{l}\text { Male } \\
\text { Married }\end{array}$ & & & & & & $0.169^{* *}$ & $\begin{array}{l}-0.005 \\
0.228 * *\end{array}$ & $\begin{array}{c}0.026 \\
-0.100 * *\end{array}$ \\
\hline $\begin{array}{l}\text { Children at } \\
\text { home }\end{array}$ & & & & & & & & $0.110^{* *}$ \\
\hline
\end{tabular}

For this table only, financial well-being is coded $3=$ Very secure, $2=$ Somewhat secure, and $1=$ Not secure. Income is coded $1=$ Less than $\$ 30,000,2=\$ 30,000-\$ 50,000,3=\$ 50,000-\$ 75,000$, and $4=A t$ least $\$ 75,000$. Standard errors used to determine significance levels take into account both within imputation variance and between imputation variance.

**Significant at the 0.01 level.

*Significant at the 0.05 level. 
Table 7. Ordered Logit Model Results for Multiple Imputation and Complete Cases

\begin{tabular}{|c|c|c|c|c|c|c|}
\hline \multirow[b]{2}{*}{ Variable } & \multicolumn{3}{|c|}{ Multiple Imputation } & \multicolumn{3}{|c|}{ Complete Cases } \\
\hline & Estimate & Std error & p-value & Estimate & Std error & $\mathrm{p}$-value \\
\hline$<\$ 30 \mathrm{~K}$ & -1.193 & 0.260 & $<0.0001$ & -1.539 & 0.265 & $<0.0001$ \\
\hline$\$ 30 \mathrm{~K}-\$ 50 \mathrm{~K}$ & -0.552 & 0.203 & 0.0067 & -0.713 & 0.229 & 0.0019 \\
\hline$\$ 50 \mathrm{~K}-\$ 75 \mathrm{~K}$ & 0.000 & 0.192 & 0.9999 & 0.057 & 0.213 & 0.7889 \\
\hline $\begin{array}{l}\text { Home owner } \\
\text { Health }\end{array}$ & 0.438 & 0.165 & 0.0081 & 0.208 & 0.184 & 0.2575 \\
\hline insurance & 0.666 & 0.173 & 0.0001 & 0.678 & 0.197 & 0.0006 \\
\hline One child & -0.427 & 0.181 & 0.0182 & -0.274 & 0.204 & 0.1802 \\
\hline $\begin{array}{l}\text { Two or more } \\
\text { children }\end{array}$ & -0.490 & 0.168 & 0.0037 & -0.386 & 0.184 & 0.0363 \\
\hline Age & -0.077 & 0.026 & 0.0033 & -0.103 & 0.029 & 0.0004 \\
\hline $\operatorname{Age}^{2}(\mathrm{x} 1000)$ & 0.742 & 0.242 & 0.0023 & 1.060 & 0.247 & 0.0001 \\
\hline College & 0.477 & 0.130 & 0.0003 & 0.523 & 0.147 & 0.0004 \\
\hline Male & -0.017 & 0.119 & 0.8883 & -0.116 & 0.135 & 0.3928 \\
\hline Not married & -0.070 & 0.148 & 0.6353 & -0.007 & 0.167 & 0.9655 \\
\hline Not working & -0.843 & 0.268 & 0.0018 & -1.178 & 0.307 & 0.0001 \\
\hline Black & -0.276 & 0.208 & 0.1847 & -0.446 & 0.249 & 0.0732 \\
\hline Intercept 1 & 0.753 & 0.725 & 0.2987 & 1.481 & 0.811 & 0.0676 \\
\hline Intercept 2 & 3.311 & 0.736 & $<0.0001$ & 4.137 & 0.823 & $<0.0001$ \\
\hline AIC & & & $2,147.1$ & & & $1,665.1$ \\
\hline R-squared & & & 0.1970 & & & 0.2390 \\
\hline Score test ${ }^{1}$ & & & 0.0755 & & & 0.5598 \\
\hline Wald $^{2}$ & & & $<0.0001$ & & & $<0.0001$ \\
\hline $\begin{array}{l}\text { Percent } \\
\text { concordant }\end{array}$ & & & 71.3 & & & 74.0 \\
\hline Sample & & & 1,148 & & & 910 \\
\hline${ }^{1}$ Test of the pr & rtional od & $\mathrm{s}$ assumpt & on $\left(\operatorname{Pr}>\chi^{2}\right.$ & & & \\
\hline${ }^{2}$ Test of the glo & l null hyp & thesis $\beta=$ & $\left(\operatorname{Pr}>\chi^{2}\right)$ & & & \\
\hline
\end{tabular}


Table 8. Predicted Probabilities for Financial Well-Being, Multiple Imputation Model and Complete Cases Model

\begin{tabular}{lcc} 
Financial well-being & $\begin{array}{c}\text { Multiple } \\
\text { imputation }\end{array}$ & Complete cases \\
\hline Very secure & 0.314 & 0.254 \\
Somewhat secure & 0.541 & 0.575 \\
Not secure & 0.145 & 0.171 \\
\hline
\end{tabular}




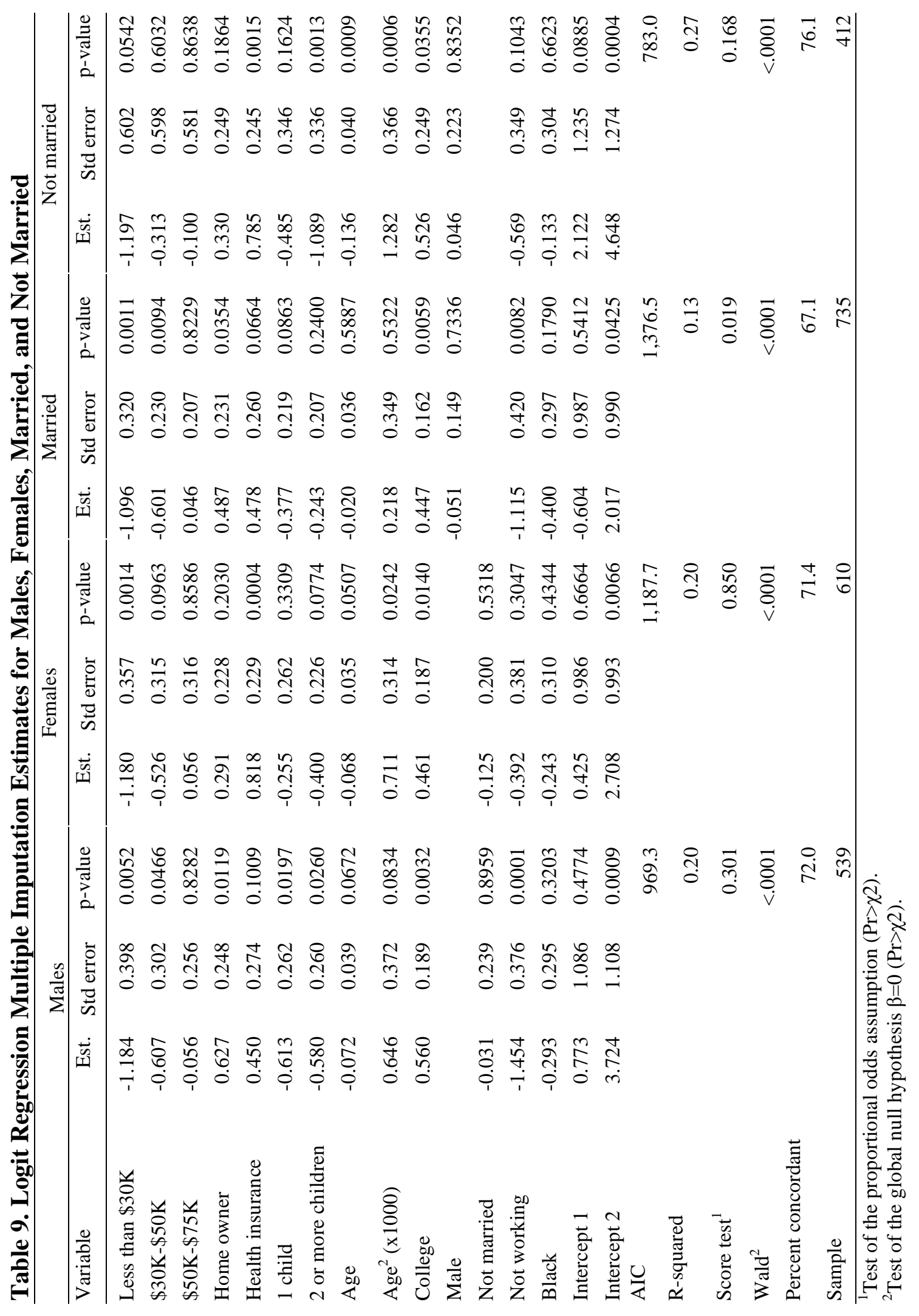


Table 10. Mean Values for Regression Variables (25 Years and Older)

\begin{tabular}{lrrrrrr} 
& & \multicolumn{5}{c}{ Multiple Imputation } \\
\cline { 3 - 8 } Variable & $\begin{array}{r}\text { Complete } \\
\text { Cases }\end{array}$ & All & Males & Females Married married \\
\hline Less than \$30K & 0.31 & 0.31 & 0.24 & 0.37 & 0.15 & 0.60 \\
\$30K-\$50K & 0.26 & 0.26 & 0.26 & 0.26 & 0.29 & 0.20 \\
\$50K-\$75K & 0.28 & 0.29 & 0.32 & 0.26 & 0.36 & 0.15 \\
Home owner & 0.76 & 0.76 & 0.80 & 0.73 & 0.85 & 0.60 \\
Health insurance & 0.82 & 0.82 & 0.84 & 0.80 & 0.90 & 0.68 \\
One child & 0.15 & 0.14 & 0.16 & 0.13 & 0.17 & 0.10 \\
Two or more & & & & & & \\
children & 0.26 & 0.23 & 0.22 & 0.25 & 0.29 & 0.13 \\
Age & 48.86 & 50.08 & 49.60 & 50.50 & 48.43 & 53.00 \\
College & 0.37 & 0.36 & 0.41 & 0.32 & 0.42 & 0.27 \\
Male & 0.49 & 0.47 & 1.00 & 0.00 & 0.53 & 0.36 \\
Not married & 0.35 & 0.36 & 0.27 & 0.44 & 0.00 & 1.00 \\
Not working & 0.06 & 0.06 & 0.08 & 0.06 & 0.03 & 0.12 \\
Black & 0.09 & 0.10 & 0.10 & 0.09 & 0.07 & 0.13 \\
\hline
\end{tabular}


Table 11. Predicted Probabilities

for Financial Well-Being by Sex, Marital Status, and the Number of Children at Home

\begin{tabular}{lrlllr}
\hline & & & & & $\begin{array}{r}\text { Not } \\
\text { All }\end{array}$ \\
& Males & Females & Married & Married \\
\hline Pr(Very Secure) & & & & & \\
No children & 0.353 & 0.360 & 0.347 & 0.405 & 0.254 \\
$\begin{array}{l}\text { One child } \\
\text { Two children }\end{array}$ & 0.263 & 0.233 & 0.292 & 0.319 & 0.173 \\
Pr(Somewhat secure) & 0.239 & 0.263 & 0.349 & 0.103 \\
No children & 0.523 & 0.555 & 0.492 & 0.498 & 0.556 \\
One child & 0.559 & 0.620 & 0.510 & 0.547 & 0.550 \\
Two children & 0.561 & 0.618 & 0.515 & 0.532 & 0.486 \\
Pr(Not secure) & & & & & \\
No children & 0.124 & 0.085 & 0.161 & 0.096 & 0.190 \\
One child & 0.179 & 0.147 & 0.198 & 0.135 & 0.276 \\
Two children & 0.188 & 0.143 & 0.222 & 0.120 & 0.411 \\
\hline
\end{tabular}

